\title{
Variability in Community Functioning of Mothers With Serious Mental Illness
}

\author{
Deborah Bybee, PhD \\ Carol T. Mowbray, PhD \\ Daphna Oyserman, PhD \\ Lisa Lewandowski, PhD
}

\begin{abstract}
In the post-deinstitutionalization era, everyday community functioning is an important aspect of assessment and treatment of individuals with serious mental illness. The current study focuses on correlates of community functioning among 332 low-income mothers with serious mental illness. Results revealed significant relationships between everyday functioning and a number of demographic, psychiatric, contextual, and mental health treatment variables. Current psychiatric symptoms accounted for the greatest amount of variance and completely mediated the effects of diagnosis and substance abuse history on community functioning; yet contextual variables such as financial worries and social support were also significant predictors, even after controlling for symptoms and other clinical characteristics. Additionally, use of mental health services was a significant moderator of the effect of social stress on community functioning. Implications of results for future research and practice are discussed.
\end{abstract}

\section{Introduction}

In the current post-deinstitutionalization era, individuals with a serious mental illness are likely to spend most of their lives in the community and to carry out normal adult roles, such as worker, student, and parent. The change in treatment settings from institution to community brings a clear shift in requirements for assessment of mental illness, whether for purposes of research or practice. Evaluating symptoms and determining diagnoses no longer provide sufficient information for developing or evaluating treatment/rehabilitation plans. Given the emphasis on community living, assessments must include information on how individuals are functioning in the community and in adult roles including work, family relationships, and maintaining a home. ${ }^{1}$ Similar shifts are required in the selection of independent variables to study as explanatory of these outcomes; assessment and explanation must take into account the context of individuals' lives, not just their past clinical history.

Address correspondence to Deborah Bybee, $\mathrm{PhD}$, Associate Professor, Department of Psychology, Michigan State University, East Lansing, MI 48824. E-mail: dbybee@umich.edu.

Carol T. Mowbray, $\mathrm{PhD}$, is Associate Dean for Research and Associate Professor at University of Michigan - School of Social Work, Ann Arbor, Michigan.

Daphna Oyserman, $\mathrm{PhD}$, is Associate Professor at School of Social Work and Department of Psychology and Associate Research Scientist in Research Center for Group Dynamics in Department of Health Management and Policy at University of Michigan - School of Social Work, Ann Arbor, Michigan.

Lisa Lewandowski, PhD, is Social Science Research Associate at University of Michigan - School of Social Work, Ann Arbor, Michigan.

Journal of Behavioral Health Services \& Research, 2003, 30(3), 269-289. (C) 2003 National Council for Community Behavioral Healthcare. 
The research reported here examines community functioning for women with serious mental illnesses who are mothers-a group significantly affected by life circumstances and stressors. The authors chose to focus on mothers because maternal functioning is known to be substantially affected by supports and resources, and because understanding correlates of adequate community functioning among mothers is important not only for the women but also for the well-being of their children. ${ }^{2,3}$ There are major policy and practice implications to this research, as mental health services infrequently attend to the parenting needs of women with serious mental illnesses. ${ }^{4-6}$

The prevalence of motherhood among women with a serious mental illness is difficult to ascertain. ${ }^{7}$ A number of international studies indicate that individuals diagnosed with schizophrenia and other related psychotic disorders have lower fecundity and fertility rates than the general population. ${ }^{8-13}$ However, these differences are not consistent across subgroups and have been found to vary by gender, diagnosis, age, marital status, and functioning level. ${ }^{1-13}$ Significant differences in fertility rates have been found less consistently for women and for individuals who are married, and they have been found less often in studies that control for counfounding variables such as age, socioeconomic status, and ethnicity. ${ }^{10}$ Caton et $\mathrm{al}^{7}$ note marked increases in fertility in the era of de-institutionalization. Even studies that have found lower fertility rates note that there are a large number of individuals with serious mental illness who are parents, particularly mothers. Recent analysis of US National Comorbidity Survey data found that among the individuals identified as having a psychiatric disorder in the past year (approximately one third of the women and one fifth of the men), $65 \%$ of the women were mothers and $52 \%$ of the men were fathers. ${ }^{14}$ Clearly parents constitute an important and large subgroup of individuals with mental illnesses. Because everyday functioning among this group has not previously been studied, we provide a brief summary of the literature on community functioning for the overall population of individuals with serious mental illnesses.

\section{Community functioning: Clinical, demographic, and contextual predictors}

Although clinical variables have been most frequently examined as predictors of variability in community functioning, their explanatory ability has not always been upheld. Psychiatric diagnosis has been an inconsistent predictor of functioning in the vocational domain. ${ }^{15-18}$ Psychiatric symptoms have been frequently found to covary with functioning, ${ }^{19-23}$ as have neurocognitive deficits for adults with schizophrenia-spectrum disorders. ${ }^{24}$ Severity and age at onset of psychiatric symptoms have also been found to relate to social functioning for men and women diagnosed with double depression (depression and dysthymia). ${ }^{25}$

However, although some studies of individuals diagnosed with schizophrenic disorders suggest that psychiatric symptoms are modest predictors of community functioning, ${ }^{20,26}$ other studies indicate that symptoms do not predict role functioning in domains such as work performance. ${ }^{19,27}$ Interpersonal problems affecting functioning have been shown to persist even when symptoms of major depression are no longer present. ${ }^{21}$ It has been suggested that apparent relationships between psychiatric symptoms and some measures of community functioning may be artificially inflated because of the similarity of items included on measures of negative symptoms and measures of social adjustment. $^{20}$

In addition to clinical variables, other individual characteristics (gender, race, premorbid adjustment, and age) are known to play a role in community functioning. Women reportedly function better overall regardless of their diagnoses ${ }^{28,29}$ perhaps because women often have more of the skills necessary for self-maintenance and independent living, ${ }^{30-33}$ as well as for fulfilling family roles, including marriage, ${ }^{31}$ childrearing, and dating. ${ }^{33}$ When functioning is assessed via social contacts and friendships, differences by gender are less consistent. ${ }^{33,34}$ Some researchers speculate that women diagnosed with mental illness function better, overall, because they are likely to have higher levels of education than do men. ${ }^{31}$ Race has been found to exert a familiar effect, as well: people diagnosed with serious mental illness who are nonwhite have lower rates of employment 
and less financial security than whites. ${ }^{34}$ Also, favorable premorbid adjustment is associated with positive social functioning, regardless of gender, ${ }^{35}$ and being older has been related to positive work status. $^{36}$

Differences in community functioning are also associated with social-contextual factors, especially social support and material stress. High functioning relates to having social support (eg, number and quality of relationships) for patient and nonpatient groups. ${ }^{37}$ Family support, specifically, is associated with better community functioning, ${ }^{36,38}$ although mental health services ${ }^{39}$ and support from treatment providers ${ }^{40}$ have also been found predictive of client functioning.

Regarding the impact of material stressors, epidemiological studies have found that as socioeconomic status (SES) decreases, the prevalence of mental disorders increases. ${ }^{41}$ Gordon and Gordon ${ }^{37}$ found a positive relationship between functioning level and SES in patient and nonpatient groups as well as a negative relationship between functioning level and financial stress. The poor are not only at increased risk of psychiatric disorder, ${ }^{42}$ but poverty status is also a stronger predictor of recurrence of psychiatric problems is than race, age, or gender. ${ }^{41,43}$

\section{Gaps in research predicting community functioning}

While most studies have focused on the relationship between clinical variables and community functioning, this brief review summarizes substantial evidence that functioning can be significantly affected by contextual/environmental variables. However, few studies have attempted to determine the strength of clinical vs environmental variables as independent predictors of community functioning. Also, although women and individuals with more support and access to social, financial, and treatment resources tend to function better on average, not enough is known about predictors of functioning within these subgroups. In the current study, we focus specifically on correlates of community functioning among low-income mothers with serious mental illness.

\section{Methods}

\section{Participants}

Participants were from a longitudinal, NIMH-funded study of mothers with serious mental illness. They were recruited from 12 Community Mental Health Centers and from the inpatient psychiatric units of 3 hospitals in southeastern Michigan. Participants were identified using a research project liaison, agency staff, and agency management information systems (MIS). To be eligible, women had to be between 18 and 55 years of age, have a severe mental illness persisting for at least 1 year and producing major dysfunction in one or more life areas, and have care responsibilities for at least 1 child aged 4 to 16 . To allow the use of a common set of parenting measures, it was necessary that all participants had experience parenting children beyond infancy; therefore, mothers whose children were all younger than 4 were excluded.

Of the 485 women identified, $379(78.1 \%)$ completed the initial interview, 46 could not be contacted or scheduled, 59 refused to be involved, and 1 died before the interview was scheduled. Of the 379 participants, 337 (88.9\% of those interviewed; $69.6 \%$ of the eligible pool) met DSM IV criteria for 1 of 6 diagnoses including schizophrenia $(10.4 \%)$, schizoaffective disorder $(10.1 \%)$, major depression (39.8\%), major depression with psychotic features (11.9\%), bipolar disorder (12.2\%), and bipolar disorder with psychotic features $(15.7 \%){ }^{*}$ The 42 women $(11.1 \%$ of the total) with no research

\footnotetext{
*Diagnoses were determined using modules from the Diagnostic Interview Schedule (DIS). ${ }^{44}$ The depression, mania, and psychosis sections of the DIS, version III-R modified for DSM-IV criteria, were used by interviewers with supervision from a PhD-level mental health professional to assure accuracy.
} 
diagnosis included 14 women who did not complete the diagnostic interview and 28 women for whom the interview yielded insufficient information for determination of a diagnosis. Other potentially important explanatory information (eg, age at onset) was unavailable for 5 additional participants. Women missing these critical variables $(n=47)$ differed from the remainder in that they exhibited higher community functioning scores $(M=3.59$ vs $3.37, t[377]=2.69, p<.01)$ and significantly fewer symptoms $(M=2.38$ vs $2.83, t[377]=-3.49, p<.01)$, suggesting that they may have had less serious mental illness. These women were omitted from the analyses reported here, resulting in the inclusion of 332 women in the present study. Demographic and psychiatric history characteristics of the sample can be found in Table 1.

\section{Interviewing}

Interviewers were all women with at least an undergraduate degree in a human service field. They were trained and supervised by an interview coordinator, who assured interview quality by reviewing audiotapes and checking completed forms. Two interview sessions were conducted with each participant, lasting about 60 to 90 minutes each (approximately 2-3 hours total). All sessions were conducted in participants' homes, and women were compensated $\$ 15$ for each of the 2 sessions required to complete the interview.

\section{Potential correlates of community functioning*}

\section{Participant demographics and background}

Demographics included age, race, total number of children, highest year of education, number of children younger than 18 , age of youngest child, parents' education, marital status, number of months at longest-held job, and prestige of most recent job based on the Hollingshead's Four-Factor Index of Social Position. ${ }^{46}$

\section{Psychiatric history, diagnosis, and symptoms}

Items included age at onset of mental illness, duration of mental illness, and history of hospitalizations (number of hospitalizations that occurred before the prior year, expressed as the average number per year since mental illness onset, in order to reduce confounding with illness duration). Substance abuse history was assessed with Skinner's Drug Abuse Screening Test ${ }^{47}$ (DAST) $(M=$ $5.12 ; \mathrm{SD}=4.8 ; \alpha=.94)$. Diagnoses were determined using modules from the DIS. ${ }^{44}$ The Colorado Symptom Index, ${ }^{48}$ a 14 -item, 5-point response scale (" 1 " = never/not at all in the last year to " 5 " = at least every day/most of the time) was used to assess the extent of current psychiatric symptoms including depression, psychosis, and paranoid symptoms $(M=2.77 ; \mathrm{SD}=0.83 ; \alpha=.90)$.

\section{Current involvement in mental health services}

Services involvement was assessed with questions adapted from the Client Resource Use instrument ${ }^{49}$ and the Access Evaluation Form. ${ }^{50}$ Level and intensity of involvement was indicated on a 6-point ordinal scale (" 0 " = no formal mental health services, " 1 " = doctor or nurse with no case management and no residential or day treatment, " 2 " = case management less than once a month with no residential or day treatment, " 3 " = case management once a month with no residential or day treatment, " $4 "=$ case management $4-8$ times in past three months, " $5 "=$ case management more

\footnotetext{
*All descriptive statistics and reliability information presented on the scales that follow were derived from the study population.
} 


\section{Table 1}

Participant characteristics, demographics, and psychiatric history

\begin{tabular}{|c|c|c|}
\hline Mother's age & Mean $=36.57$ & $\mathrm{SD}=6.67$ \\
\hline Number of children & Mean $=2.88$ & $\mathrm{SD}=1.52$ \\
\hline Age of children ( $N=956$ children $)$ & Mean $=11.00$ & $\mathrm{SD}=7.35$ \\
\hline \multicolumn{3}{|l|}{ Mother's living situation } \\
\hline Alone with children & 162 & $48.8 \%$ \\
\hline With spouse/partner & 106 & $31.9 \%$ \\
\hline With extended family & 48 & $14.5 \%$ \\
\hline Alone* & 16 & $4.8 \%$ \\
\hline \multicolumn{3}{|l|}{ Mother's race } \\
\hline African American & 198 & $59.6 \%$ \\
\hline Caucasian & 103 & $31.0 \%$ \\
\hline Hispanic & 25 & $7.5 \%$ \\
\hline Other & 6 & $1.8 \%$ \\
\hline \multicolumn{3}{|l|}{ Mother's education } \\
\hline Less than high school graduation & 113 & $34.0 \%$ \\
\hline Graduated from high school & 87 & $26.2 \%$ \\
\hline More than high school & 132 & $39.8 \%$ \\
\hline Family income (as percent of poverty line) ${ }^{\dagger}$ & Mean $=96$ & $\mathrm{SD}=55$ \\
\hline Mother's age at onset of mental illness & Mean $=26.97$ & $\mathrm{SD}=8.31$ \\
\hline $\begin{array}{l}\text { Years since mother's diagnosis/1st psychiatric } \\
\text { hospitalization }\end{array}$ & Mean $=10.17$ & $\mathrm{SD}=7.52$ \\
\hline Number of psychiatric hospitalizations (lifetime) & Mean $=4.16$ & $\mathrm{SD}=7.71$ \\
\hline $\begin{array}{l}\text { Average psychiatric hospitalizations per year } \\
\text { since mental illness onset }\end{array}$ & Mean $=0.46$ & $\mathrm{SD}=0.60$ \\
\hline Number of hospitalizations in year prior to interview & Mean $=0.55$ & $\mathrm{SD}=1.01$ \\
\hline \multicolumn{3}{|l|}{ Mental illness onset relative to childbirth } \\
\hline All children born before onset & 143 & $43.0 \%$ \\
\hline All children born after onset & 66 & $20.0 \%$ \\
\hline Onset within $1.5 \mathrm{y}$ of birth & 89 & $27.0 \%$ \\
\hline Onset between births & 34 & $10.0 \%$ \\
\hline \multicolumn{3}{|l|}{ Mother's diagnosis } \\
\hline Major depression & 132 & $39.8 \%$ \\
\hline Major depression with psychotic features & 39 & $11.7 \%$ \\
\hline Bipolar disorder & 40 & $12.0 \%$ \\
\hline Bipolar disorder with psychotic features & 53 & $16.0 \%$ \\
\hline Schizophrenia & 35 & $10.5 \%$ \\
\hline Schizoaffective disorder & 33 & $9.9 \%$ \\
\hline
\end{tabular}

*Although these mothers did not live with their children, they had care responsibilities for one or more children at least 1 day per week.

${ }^{\dagger}$ Federal poverty line in $1996=\$ 12,641$ for a family of $4 .{ }^{45}$

than 8 times in past three months, and " 6 " = residential/day treatment; $M=3.4 ; \mathrm{SD}=1.8$ ). Also included were the number of mental health providers listed as a source of positive social support $(M=0.66 ; \mathrm{SD}=0.92)$ (based on the Arizona Social Support Interview Schedule ${ }^{51}$ ) and the number of hospitalizations in the prior year $(M=0.53 ; \mathrm{SD}=0.95)$. 


\section{Material stressors and resources}

Material context variables included adjusted income (total family income weighted by family size and reported as a percent of the poverty line ${ }^{45}$ ); number of areas of financial worry experienced in the past 3 months $(M=3.99 ; \mathrm{SD}=2.50 ; \alpha=.80)$ assessed using the 8-item Financial Worries Scale $^{52}$; a scale of the financial stress caused by 8 money-related items $(M=1.99 ; \mathrm{SD}=0.58 ; \alpha=$ .76) from the Hassles and Uplifts Scale ${ }^{53,54}$; and a count of the 6 money-related negative life events experienced from the Brief Life Events Questionnaire ${ }^{55}(\mathrm{M}=1.52 ; \mathrm{SD}=1.2){ }^{*}$

\section{Social stressors and resources}

Social context variables included type of living situation, the number of people listed as available for positive social support $(M=6.83$; SD $=3.30)$ from the Arizona Social Support Interview Schedule, ${ }^{51}$ a scale of social stress caused by the 7 interpersonal items $(M=1.80 ; \mathrm{SD}=0.51 ; \alpha=$ .73) from the Hassles and Uplifts Scale, ${ }^{53,54}$ and a count of the 6 negative interpersonal life events experienced $(M=1.76 ; \mathrm{SD}=1.2)$ from the Brief Life Events Questionnaire. ${ }^{55, *}$ Religion as a source of support was measured in 2 different ways ${ }^{57}$ : one item captured the frequency of attending religious services (" 1 " = never, " 2 " = less than once a month, " 3 " = monthly, " 4 " = weekly, " 5 " = more than once weekly; $M=2.73 ; \mathrm{SD}=1.30$ ). Religiosity was assessed as the mean of 2 items ("How religious are you?" and "How much is religion/God a source of comfort?"), rated on a scale from 1 to 4 ("1" = none to " $4 "$ " = a great deal; $M=3.33 ; \mathrm{SD}=0.61 ; \alpha=.55$ ).

\section{Community functioning}

Typically, community functioning measures are adapted to suit the particular population of interest. ${ }^{1,58,59}$ Reviews of community functioning scales ${ }^{1,58,59}$ highlight limitations of existing measures, which typically take more than 20 minutes to administer, are not self-report, and do not cover a full array of interpersonal and social roles. Although there is potential for bias, self-reports can be the most direct way to access reliable information about individuals. ${ }^{59}$ Moreover, self-reports give voice to participants' viewpoints and do not rely on informants who may have inadequate knowledge of individuals' daily activities in a wide variety of functioning domains. ' In the current study, the self-report community functioning measure was relevant to the lives of mothers living in the community.

The Self-report Community Functioning Scale assesses behaviors and activities occurring in the past month (see Appendix Table). The 18 items address important domains of community life including managing a household; engaging in productive activity; interacting with friends and family; communicating with other people; controlling one's actions and handling crises; maintaining mental and physical health; and avoiding substance abuse. Each item is answered along a 5-point scale tailored to the content of the question, where " 1 " reflects no activity in the domain and " 5 " reflects frequent independent activity in the domain $(M=3.37 ; \mathrm{SD}=0.54 ; \alpha=.80)$. Evidence of convergent validity was demonstrated through significant correlations in the expected direction with other selfreport measures including the Colorado Symptom Inventory $(r=-0.64)$, Global Quality of Life $(r=0.61)$, and Parenting Stress Index $(r=-0.30)$. Moderate convergence was also found with mental health professionals' ratings on Global Assessment of Functioning $(r=0.24)$ and a Case-manager Rating of Community Functioning Scale $(r=0.33)$, an instrument that parallels the Self-Report Functioning Scale. ${ }^{60}$

\footnotetext{
${ }^{*}$ Because counts of life events and social support sources are conceptualized as causal rather than effect indicators, ${ }^{56}$ internal consistency is not reported for these variables.
} 


\section{Analysis plan}

Prior to analysis, we log transformed the few variables with skewed distributions (number of hospitalizations, number of people available for positive social support, and number of mental health providers listed as sources of positive social support) to better meet normality assumptions of the analysis and to limit the influence of extreme scores. Data analysis consisted of 2 steps. First, Pearson product-moment correlations were performed to identify significant bivariate relationships between potential correlates (demographics and background, diagnoses, psychiatric history, symptoms, material stressors and resources, social stressors and resources, mental health services involvement) and current community functioning. For categorical covariates, the $\eta$ (eta) statistic and Tukey paired comparison results were examined.

Second, correlates were entered in blocks into a hierarchical regression analysis, with a planned order of entry reflecting increasing mutability and amenability to intervention. The hierarchical method allowed systematic assessment of the unique and joint contributions of each block. Demographic variables were entered first to account for stable individual characteristics that are frequently found to covary with functioning in various domains and in diverse populations (eg, age, race, gender, education). To capture variability associated with relatively immutable psychiatric characteristics, diagnosis and psychiatric history were entered in blocks 2 and 3. In block 4, extent of current symptoms was entered, reflecting the more variable aspects of an individual's' psychiatric condition, after controlling for the effects of stable psychiatric characteristics and history. Blocks 5 and 6 entered descriptors of an individual's current context-stressors and resources in the material domain (block 5) and in the social domain (block 6). Finally, current involvement in mental health services was entered in the last block, to assess its explanatory contribution once all other sources of influence were controlled.

Because the impact of mental health services may depend on the amount of presenting difficulty, a final, exploratory block examined mental health services involvement as a potential moderator of the effects of psychiatric history and status (ie, time since mental illness onset, current psychiatric symptoms, substance abuse history) and the impact of material and social context (ie, financial worries, social support, and social stress). Interactions between each of these 6 variables and mental health services involvement were entered into a final block following the main effect for mental health services involvement. Because this step of the analysis was exploratory, significance tests for these interaction terms were Bonferroni-adjusted for 6 tests. Variables involved in interaction terms were centered to facilitate interpretation, and the main effects of interacting variables were included in the equation. Interpretation followed procedures described by Aiken and West ${ }^{61}$ for testing, graphing, and probing interaction terms.

\section{Results}

\section{Bivariate analyses}

\section{Demographic and background variables}

As can be seen in Table 2, only 4 of 11 demographic and background variables were related to self-reported community functioning. Participants reported higher levels of community functioning if they were more highly educated, had spent more time at their longest-held job, were older, and had fewer children younger than 18 , although the latter 2 results were significant only at trend level $(p<.10)$.

\section{Diagnosis, psychiatric history, and symptoms}

Diagnosis, duration of mental illness, a history of substance abuse, and the extent of current symptoms all related to community functioning. Specifically, women with schizoaffective disorder 
Table 2

Bivariate relationships between everyday community functioning and participant demographics, psychiatric history, material and social stressors and resources

\begin{tabular}{|c|c|}
\hline Variables related to self-reported community functioning & Relationship* \\
\hline \multicolumn{2}{|l|}{ Background and demographics } \\
\hline Age & $r=0.09^{\dagger}$ \\
\hline Marital status & $\eta=0.12$ \\
\hline Race & $\eta=0.09$ \\
\hline Children younger than 18 & $r=-0.11^{\dagger}$ \\
\hline Total number of children & $r=-0.04$ \\
\hline Age of youngest child & $r=0.04$ \\
\hline Father's highest education & $r=0.02$ \\
\hline Mother's highest education & $r=0.02$ \\
\hline Education & $r=0.22^{\ddagger}$ \\
\hline Months at longest-held job & $r=0.15^{\S}$ \\
\hline Prestige of most recent job & $r=0.02$ \\
\hline Diagnosis & $\eta=0.20^{\S}$ \\
\hline \multicolumn{2}{|l|}{ Psychiatric history } \\
\hline Mental illness onset (5 or more years ago) & $r=0.17^{\S}$ \\
\hline Age at onset of mental illness & $r=-0.01$ \\
\hline Hospitalizations before prior year & $r=0.04$ \\
\hline Substance abuse history & $r=-0.16^{\S}$ \\
\hline Psychiatric symptoms & $r=-0.64^{\ddagger}$ \\
\hline \multicolumn{2}{|l|}{ Material stresses and resources } \\
\hline Income (adjusted for household size) & $r=0.23^{\ddagger}$ \\
\hline No. of areas of financial worry & $r=-0.35^{\ddagger}$ \\
\hline Financial stress & $r=-0.35^{\ddagger}$ \\
\hline Money-related negative life events & $r=-0.19^{t}$ \\
\hline \multicolumn{2}{|l|}{ Social stressors and resources } \\
\hline No. of available positive social supports & $r=0.19^{\ddagger}$ \\
\hline Living situation & $\eta=0.19^{\S}$ \\
\hline Social stress due to interpersonal hassles & $r=-0.32^{\ddagger}$ \\
\hline Negative interpersonal life events & $r=-0.17^{\S}$ \\
\hline Church attendance & $r=0.25^{\ddagger}$ \\
\hline Religiosity & $r=0.11^{\|}$ \\
\hline \multicolumn{2}{|l|}{ Current Mental Health Services } \\
\hline Level of mental health service involvement & $r=-0.16^{\S}$ \\
\hline Mental health providers as positive social support & $r=-0.11^{\dagger}$ \\
\hline Hospitalizations in the past year & $r=-0.08$ \\
\hline
\end{tabular}

Note: $N=332$.

${ }^{*}$ Pearson product-moment correlations are reported for ordinal and interval variables; $\eta$ (eta) is reported for categorical variables. Tukey paired comparison tests revealed better community functioning for women with schizophrenia $(p<.01)$ and bipolar disorder $(p<.10)$ compared with women with schizoaffective disorder; and better functioning for women who lived alone, compared to those living with children only $(p<.01)$ or with a partner $(p<.05)$.

${ }^{\dagger} p<.10$.

${ }^{\ddagger} p<.001$.

${ }^{\S} p<.01$.

$\| p<.05$. 
reported lower functioning than did those diagnosed with schizophrenia $(p<.01)$ or bipolar disorder $(p<.10)$. For duration of mental illness, graphical inspection showed a positive relationship with community functioning that was not uniformly linear. Community functioning improved in a linear association with duration through the first 5 years after mental illness onset. Above 5 years, duration of mental illness appeared unrelated to community functioning. To reflect this relationship, the duration variable was dichotomized. Women who had lived with a mental illness for 5 or more years $(n=99 ; 70.2 \%)$ reported better community functioning than did those who had been ill for fewer than $5(n=233 ; 29.8 \%)$.

With regard to substance abuse history, women who reported a more extensive history of alcohol and/or drug abuse were lower in current community functioning. Although a higher number of hospitalizations and earlier onset have sometimes been implicated as covariates of worse functioning, ${ }^{25}$ in our sample, age at onset and lifetime hospitalizations adjusted for illness duration were unrelated to community functioning. Current symptomatology was strongly related, however, with women who reported higher levels of current psychiatric symptoms significantly lower in community functioning.

\section{Material stressors and supports}

All of the material stressor and resource variables correlated significantly with community functioning. Women with higher adjusted household incomes and fewer financial worries or moneyrelated negative events and those reporting lower financial stress were higher in current community functioning.

\section{Social stressors and resources}

All of the social stressor and resource variables correlated significantly with community functioning. Women who attended church regularly, perceived themselves as religious, or identified more sources of available positive social support had better community functioning, and those with higher social stress or more negative life events in the social domain had worse functioning. Women who lived alone reported significantly higher levels of community functioning than did those who lived with their children and no other adults or with a partner (with or without children).

\section{Mental health service involvement}

Level of mental health service involvement showed a negative linear relationship with current community functioning. That is, more intensive service use was associated with worse functioning. Related to this, women who listed more mental health providers as sources of positive support were also marginally lower in community functioning $(p<.10)$. Number of hospitalizations in the past year was not significantly related to level of current community functioning.

\section{Hierarchical regression analysis}

As described in the analysis plan, each of the above blocks of variables was entered into a hierarchical regression equation. Within each successive block, variables that did not make a significant unique contribution to the prediction of functioning, controlling for the explanatory contribution of variables in previous blocks, were trimmed from the equation. To control for potential confounds, basic demographic variables (age, education, race, and number of children younger than 18) were included in the hierarchical regression analysis regardless of their significance to prediction.

Results of the hierarchical regression analysis are presented in Table 3. To allow examination of mediated effects, coefficients from both the entry and final blocks are included-entry block coefficients reflect a variable's relationship with functioning, controlling for the effects of variables entered previously into the equation; final block coefficients are adjusted for the effects of all other variables entered into the equation at any block. With the exception of the main effect for mental 
Table 3

Hierarchical regression explaining variability in community functioning

\begin{tabular}{|c|c|c|c|c|c|c|}
\hline \multirow[b]{2}{*}{ Predictor blocks } & \multicolumn{2}{|c|}{ Entry block } & \multicolumn{2}{|c|}{ Final block } & \multirow[b]{2}{*}{ Adjusted $R^{2}$} & \multirow[b]{2}{*}{ Adjusted $\Delta R^{2}$} \\
\hline & $\beta$ & $t$ & $\boldsymbol{\beta}$ & $t$ & & \\
\hline 1. Background and demographics & & & & & $.05^{*}$ & $.05^{*}$ \\
\hline Age & .05 & 0.98 & -.05 & -1.22 & & \\
\hline $\begin{array}{l}\text { Number of children } \\
\text { younger than } 18\end{array}$ & -.06 & -1.12 & -.05 & -1.22 & & \\
\hline Education & .21 & $3.69^{*}$ & .10 & $2.35^{\dagger}$ & & \\
\hline Black & .09 & -1.54 & -.17 & $-3.73^{*}$ & & \\
\hline Hispanic & .02 & 0.39 & .03 & 0.65 & & \\
\hline 2. Diagnosis & & & & & $.07^{\dagger}$ & $.02^{*}$ \\
\hline $\begin{array}{l}\text { Schizoaffective (omitted } \\
\text { comparison) }\end{array}$ & $\cdots$ & $\cdots$ & $\cdots$ & $\cdots$ & & \\
\hline Schizophrenia & .23 & $3.13^{\ddagger}$ & .01 & 0.18 & & \\
\hline Depression & .18 & $1.93^{\S}$ & .01 & 0.12 & & \\
\hline $\begin{array}{l}\text { Depression with psychotic } \\
\text { features }\end{array}$ & .13 & 1.72 & .05 & 0.96 & & \\
\hline Bipolar disorder & .17 & $2.24^{\dagger}$ & .06 & 1.01 & & \\
\hline $\begin{array}{l}\text { Bipolar with psychotic } \\
\text { features }\end{array}$ & .07 & 0.85 & -.01 & -0.10 & & \\
\hline 3. Psychiatric history & & & & & $.11^{*}$ & $.04^{*}$ \\
\hline $\begin{array}{l}\text { Mental illness onset } \\
\text { (5 or more years ago) }\end{array}$ & .17 & $3.07^{\ddagger}$ & .13 & $2.96^{\ddagger}$ & & \\
\hline Substance abuse history & -.16 & $-3.04^{\ddagger}$ & -.07 & -1.60 & & \\
\hline 4. Psychiatric symptoms & -.60 & $-13.06^{*}$ & -.47 & $-10.0^{*}$ & $.42^{*}$ & $.31^{*}$ \\
\hline $\begin{array}{l}\text { 5. Material stressors and } \\
\text { resources }\end{array}$ & & & & & $.47^{*}$ & $.05^{*}$ \\
\hline No. of areas of financial worry & -.23 & $-5.23^{*}$ & -.20 & $-4.58^{*}$ & & \\
\hline 6. Social stressors and resources & & & & & $.49^{*}$ & $.02^{*}$ \\
\hline $\begin{array}{l}\text { No. of available positive social } \\
\text { supports }\end{array}$ & .11 & $2.50^{\dagger}$ & .11 & $2.50^{\dagger}$ & & \\
\hline Social stress (due to hassles) & -.11 & $-2.41^{\dagger}$ & -.11 & $-2.41^{\dagger}$ & & \\
\hline Church attendance & .08 & $1.90^{\S}$ & .08 & $1.90^{\S}$ & & \\
\hline
\end{tabular}

Note: $N=332$.

${ }^{*} p<.001$.

${ }^{\dagger} p<.05$.

$\ddagger_{p} p<.01$.

$\S p<.10$.

health service involvement, all blocks made significant independent contributions to the explanation of community functioning. Collectively, the variables in all blocks explained 50\% (adjusted) of the variance in current community functioning.

In the final model, 2 demographic variables, education $(\beta=.10)$ and race $(\beta=-.17)$, were both significant predictors of functioning. Women with higher levels of education were functioning better, and African American women were functioning worse, compared with Caucasian women. The effect of education had been found in the bivariate analysis, but the effect of race emerged only in the final block of the multivariate analysis, after controlling for the effects of variables that 
were confounded (correlated) with race in this sample. Because race did not have a simple bivariate relationship with community functioning, further analysis was conducted to explain the nature of this relationship. In the current sample, race was confounded with psychiatric variables (diagnosis, mental illness duration, and substance abuse history) and with material stresses and resources. Specifically, being black was significantly related to diagnosis $\left(\chi^{2}[1, N=332]=12.63, p<.05\right)$, with African Americans overrepresented among those with schizophrenia (14.6\% vs $4.5 \%)$ and underrepresented among those with major depression (34.7\% vs 46.6\%). African Americans also had longer average duration of mental illness, with $74.4 \% 5$ years or longer, compared with $63.9 \%$ of non-African Americans $\left(\chi^{2}[1, N=332]=4.17, p<.05\right)$, and they reported fewer past problems with substance abuse $(M=4.65$ vs $5.82, t[332]=2.20, p<.05)$. Finally, African Americans reported fewer financial worries than did non-African Americans $(M=3.68$ vs $4.46, t[332]=2.82, p<.01)$. Maintaining race in the first block of the equation adjusted for these confounds and allowed inspection of the effects of diagnosis, duration of mental illness, substance abuse history, and financial worries with the effects of race controlled.

When entered at blocks 2 and 3, diagnosis and psychiatric history (mental illness duration and substance abuse history) were significantly related to community functioning. For diagnosis, schizoaffective disorder was used as the comparative category because of evidence that mothers diagnosed with schizoaffective disorder showed more impairment on a number of variables compared with mothers who had other diagnoses. ${ }^{62}$ At the entry block, women diagnosed with schizophrenia $(\beta=.23)$ or bipolar disorder $(\beta=.17)$ had significantly higher functioning scores than women with schizoaffective disorder; women diagnosed with major depression had marginally better functioning $(\beta=.18)$. Also, women who had a mental illness for 5 or more years $(\beta=.17)$ and those with fewer past problems with substance abuse $(\beta=-.16)$ reported higher community functioning. Diagnosis and substance abuse history were not related $(F=1.58, p=.165)$.

Although some variance was explained by demographics (adjusted $\Delta R^{2}=0.05$ ), diagnosis (adjusted $\Delta R^{2}=0.02$ ), and psychiatric history variables (adjusted $\Delta R^{2}=0.04$ ), the largest contributor to variability in community functioning was current psychiatric symptoms, entered at block 4 (adjusted $\Delta R^{2}=0.31$ ). Once the symptoms block was entered, diagnosis and substance abuse history, both of which were significantly related to symptoms, no longer made significant, unique contributions to the explanation of community functioning. Given that diagnosis and substance abuse history were significantly related to both community functioning and symptoms, symptom presentation can be said to completely mediate or explain the effects of diagnosis and substance abuse history on functioning. ${ }^{63}$ In contrast, the coefficient for mental illness duration showed little change and remained significant after extent of current symptoms was entered into the equation, indicating that its effect was not substantially mediated and suggesting that the association between illness duration and community functioning was independent of any effect duration of mental illness may have on symptom amelioration.

Both blocks of stressor and resource variables (material and social) added significantly to the explanation of community functioning. The single variable that captured the largest effect of material stressors and resources was financial worries $\left(\beta=-.23\right.$; adjusted $\left.\Delta R^{2}=0.05\right)$; women with more financial worries showed poorer community functioning. The social stressors and resources block included several significant explanatory variables (adjusted $\Delta R^{2}=0.02$ ). Specifically, women with more sources of positive support $(\beta=.11)$ and lower social stress $(\beta=-.11)$ reported better community functioning. Moreover, women who attended church more frequently $(\beta=.08)$ also reported better community functioning (at trend-level significance).

After variables in the previous blocks had been entered and their effects accounted for, no unique effect was found for mental health service involvement. Although perhaps surprising at first glance, it is likely that services made no additional contribution to prediction of functioning differences because individuals' service use was related to a number of the variables already in the equation. Service use was significantly associated with having a recent onset of mental illness $(r=0.14)$, a 
history of substance abuse ( $r=0.15)$, more current symptoms $(r=0.15)$, and more financial worries $(r=0.19)$ - variables already taken into account in the analysis.

Although mental health service involvement had no linear relationship with functioning, it was possible that services might act as a moderator, buffering the impact of stressors or aspects of mental illness. Exploratory analyses examined service use as a potential moderator of the impact of 6 psychiatric and contextual variables reflecting need for services-recency of mental illness onset, substance abuse history, psychiatric symptoms, financial worry, available social supports, and social stress. Service use was found to significantly moderate the negative impact of social stress; adding the interaction between social stress and mental health services in a final block, following the (nonsignificant) main effect for services, made a small but significant explanatory contribution (adjusted $\Delta R^{2}=0.01, p<.001$; Bonferroni-adjusted [for tests of 6 interaction terms] $p<.01)$.

Following standard procedures for examining interactions in a regression context, ${ }^{61}$ simple slopes were calculated for the continuous effect of each of the 2 interacting variables at high and low points along the distribution of the other variable-1 SD above and 1 SD below the mean. Graphical exploration of the interaction (see Fig 1) showed that community functioning was negatively related to social stress for women receiving lower levels (1 SD below the mean, roughly equivalent to case management less than once per month) of mental health services; unstandardized $B$ for the simple slope $=-0.30, p<.001$, equivalent to a 0.59 SD difference in functioning between women reporting high $(M+1 \mathrm{SD})$ vs low $(M-1 \mathrm{SD})$ levels of social stress. For women receiving higher levels of mental health services ( 1 SD above the mean, roughly equivalent to case management 3 or more

\section{Figure 1}

Community functioning by social stress at high and low levels of mental health service use

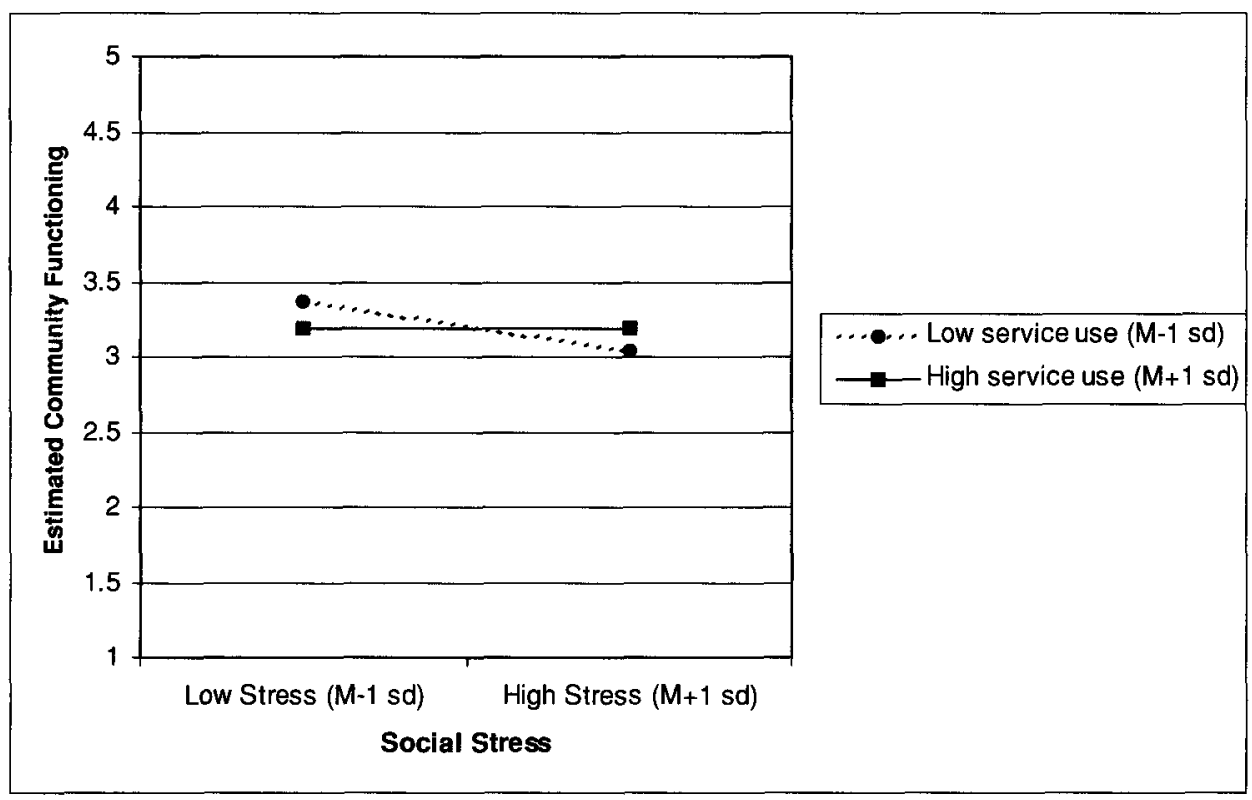

Note: Community Functioning Scores range from 1 to 5 , where "1" reflects no activity in the functioning domain and " 5 " reflects frequent independent activity in the domain. 
times per month), functioning did not depend on level of social stress; unstandardized $B$ for the simple slope $=-0.01, p=.87$.

\section{Discussion}

Results of the present study revealed significant bivariate relationships between community functioning and a number of demographic, psychiatric, and mental health treatment involvement variables, as well as all contextual variables (eg, income, financial worries, social stress, and social support). The most significant contribution this study makes to the literature comes from the hierarchical regression analysis, which controlled for demographic variables and enabled examination of contextual variables once the effects of historical and current clinical variables had been accounted for. This analysis showed that diagnosis and substance abuse history made no additional contribution to the explanation of community functioning once symptoms had been entered into the regression equation; symptoms completely mediated the effects of these variables. Further, although current psychiatric symptoms explained the greatest amount of variance in community functioning, contextual variables were significant explanatory variables, even after controlling for demographics, psychiatric history, diagnosis, and current symptoms. Controlling for the effects of these other variables, mental health services involvement had no simple main effect on community functioning. Instead, mental health services involvement appeared to buffer the negative effects of social stress.

\section{Community functioning and demographics/background}

Congruent with previous research, ${ }^{36,64}$ mothers with more education and stable employment histories were functioning better. In contrast to previous research showing poorer employment outcomes for nonwhite individuals, ${ }^{34}$ bivariate analyses showed no functioning differences by race. However, racial effects did emerge once the impact of psychiatric (eg, diagnosis, mental illness duration, substance abuse history) and financial stressor variables was removed. Controlling for the effects of these variables, African American mothers reported poorer functioning compared with non-African American mothers. This residual effect may be due to the configuration of the current sample, which is unusual in the high percentage of African Americans present. It may also reflect contextual stressors that were not explicitly included in the equation, such as the pernicious effects of racism and discrimination. Anderson amd Armstead ${ }^{65}$ have noted race disparities in health morbidity and mortality even controlling for economic levels.

\section{Community functioning and mental health}

Consistent with other research, ${ }^{20,25,39,66-68}$ our study found that community functioning, diagnosis, duration of mental illness, and substance abuse history were related. In our analysis, current psychiatric symptoms explained the largest amount of variance in community functioning and mediated (or explained) the relationships between community functioning and psychiatric history variables such as diagnosis and substance abuse history. Previous studies that provide contradictory evidence, claiming that psychiatric symptoms have a minimal impact on functioning, are probably limited because of methodological issues-functioning measures restricted to a single domain such as employment status ${ }^{19}$ or social relationships. ${ }^{21}$ Although these contradictory findings could be due to methodological differences, inconsistent results across studies could also be due to failure to account for factors other than psychiatric history and symptoms (eg, race/ethnicity, gender, or education).

Duration of mental illness remained positively associated with community functioning even when the effects of other demographic, psychiatric, and contextual variables were controlled. In contrast to diagnosis and substance abuse history, the effect of duration was not mediated by current symptoms, suggesting that the impact of mental illness duration on community functioning was independent of 
any effect that the passage of time might have on symptom amelioration. This result, along with the finding that the positive relationship between duration and functioning leveled off approximately 5 years following onset, is consistent with observations from qualitative research about "plateaus" in functioning as individuals learn to manage aspects of their mental illness. ${ }^{68,69}$

\section{Community functioning and contextual stressors and resources}

Research on individuals with serious mental illness often neglects contextual variables such as poverty ${ }^{70}$ and social stress, despite evidence that these forces may have direct effects on community functioning in the general population as well as among individuals coping with disability and illness. ${ }^{71-74}$ Consistent with other research, ${ }^{37}$ the authors found that financial stress was related to community functioning even after controlling for demographic and psychiatric variables. This is also congruent with the research findings that lack of financial resources is a better predictor than psychological factors for identifying families in need of community and mental health interventions. ${ }^{74,75}$ Also consistent with other research, ${ }^{37}$ greater social stress was associated with poorer community functioning, and greater social support related to better functioning. Although higher church attendance was related to better community functioning only at a trend level, this finding is congruent with other research demonstrating that religious activities facilitate adaptation to the demands of community life. ${ }^{76,77}$

\section{Community functioning and mental health service involvement}

In this study, the relationship between mental health service involvement and community functioning was complex. The negative bivariate association suggested that more intensive mental health services were being provided to mothers with greater functioning difficulty. However, when the effects of other variables were considered, this direct relationship disappeared and a nonlinear relationship emerged in which higher involvement in services moderated the effects of social stress. For women receiving lower levels of mental health services, functioning was significantly negatively related to social stress, but for women at higher levels of service involvement, functioning was unrelated to social stress. This suggests that involvement in relatively intensive services may help to buffer the effects of social stress, preventing it from having a deleterious effect on community functioning.

\section{Strengths and limitations of the research}

A majority of our bivariate findings are consistent with the published literature. Divergent findings may be due to methodological differences across studies. Our sample was composed of predominantly minority, low-income mothers with a range of diagnoses indicative of serious mental illness. Diagnoses were determined from a standardized research assessment. Many differences between this study's results and others could be due to our multivariate focus. We controlled for race and educational variability in our analyses, and we examined the effects of material and social stressors and resources. Conversely, much of the research in this area has examined select or homogeneous diagnostic, socioeconomic, and/or racial groups (eg, focusing more on middle class Caucasians and on individuals with a diagnosis of schizophrenia). Possible confounds due to race or poverty have rarely been explored in other studies, and mental health services as moderators of the impact of stress have not been considered. Moreover, samples have typically included both men and women and have not explored issues relevant to women in particular. Differences in diagnostic criteria, as well as variability on other dimensions such as mental health interventions and definitions of clinical improvement, have also contributed to diverse results. ${ }^{78}$

Several limitations require consideration when drawing inferences from results. First, the analysis should be replicated in other samples. The search for moderating effects of mental health services was 
exploratory, and the effects identified as significant but small in this study should be examined in a confirmatory sample. Second, the analyses utilized cross-sectional data, which do not permit inferences about causal direction or the effects of time. Third, most of the measures come from the perspective of the participants. For example, the assessment of financial worries did not include an objective measure of participants' debts. However, while the potential for participant bias exists with the use of any self-report measure, self-reports have been found to be reliable and direct sources of information, in this case providing unique insight into daily activities and perspectives. ${ }^{1,59} \mathrm{~A}$ fourth possible limitation is that the strong relationship between symptoms and community functioning could partially reflect a methods confound, resulting from asking potentially similar questions in the same format. However, in this study, the content of the questions differed substantially between the 2 measures (see Appendix Table), and the response choices differed as well. A final limitation is that the study results may not generalize to all women with serious mental illnesses, in that there is some evidence that those female consumers who bear children and continue care responsibilities for them may have higher functioning levels than women who do not carry out the maternal role. ${ }^{79}$ Additionally, $21.9 \%$ of the women identified as eligible were not able to be interviewed; those who participated might be functioning better than women who refused or could not be located.

\section{Implications for Behavioral Health Services}

Clearly, these results have practice implications, beginning with the need for interventions to address poverty and social stressors as well as current symptoms. Anderson and Armstead ${ }^{65}$ challenge health researchers to take a role in developing interventions to improve SES, eg, approaches that move people out of poverty-such as increasing education, providing training, or increasing skills. Specifically, interventions may be needed to enhance money management skills, help individuals secure a stable income, and facilitate access to resources (low cost food, housing, etc.)-especially since this group of women, as mothers, are responsible for the welfare of their children, and they often function as single parents. Services such as family support, psychoeducation, and peer support through parenting and other groups may facilitate better functioning for mothers with serious mental illness by reducing social stressors and increasing social supports. Unfortunately, a number of publications have documented the fact that mental health providers pay little attention to parenting issues for adults with serious mental illnesses. ${ }^{4-6,80}$

That involvement in more intensive mental health services appeared to buffer the deleterious effects of social stress suggests that higher intensity services could be especially beneficial to women in high stress relationships or situations, which probably typifies the situations of consumers who are single parents and living in poverty. Mothers who are having functioning difficulties and whose social contexts involve high stress levels may also have trouble remaining engaged in mental health services; transportation, outreach, availability of child-care, or assertive efforts to maintain service engagement might also be helpful. Finally, assessment and treatment for current psychiatric symptoms appear critical for improving community functioning, which should be a necessary prerequisite for adequate parenting.

Regarding future research, these results strengthen our belief in the use of multiple domain measures in areas relevant to the population in question (eg, work, daily living, social interactions). ${ }^{81}$ Our findings further highlight the need for analyses to control for background and demographic variables in order to better determine the effects of variables such as support, stress, and service use. Exploration of mediating and moderating relationships is also important in order to understand the complex relationships involving the demographic, psychiatric, contextual, and service variables associated with community functioning. While the current results are promising, of course they should be confirmed through investigations that include longitudinal data sets, other measures assessing multiple domains of community living, and diverse samples including women and men from heterogeneous backgrounds, examining gender differences and gender interactions. 


\section{Acknowledgment}

This research was funded by \#R01MH54321, a grant from the National Institute of Mental Health, to the second author.

\section{References}

1. Dickerson FB. Assessing clinical outcomes: the community functioning of persons with serious mental illness. Psychiatric Services. 1997:48:897-902.

2. Gross D. Relationships at risk: issues and interventions with the disturbed mother-infant dyad. Perspectives in Psychiatric Care. 1984;21:159-164.

3. Sands RG. The parenting experience of low-income, single women with serious mental disorders. Families in Society-The Journal of Contemporary Human Services. 1995;76:86-96.

4. Apfel RJ, Handel MH. Madness and Loss of Motherhood. Washington, DC: American Psychiatric Association Press Inc; 1993.

5. Cogan J. Assessing the Community Support Services Needs That Women With Psychiatric Disabilities May Have Regarding Relationships. Burlington, Vt: Center for Community Change Through Housing and Support; 1993.

6. Zemencuk J, Rogosch FA, Mowbray CT. The seriously mentally-ill woman in the role of parent: characteristics, parenting sensitivity, and needs. Psychosocial Rehabilitation Journal. 1995;18:77-92.

7. Caton CLM, Cournos F, Felix A, et al. Childhood experiences and current adjustment of offspring of indigent patients with schizophrenia. Psychiatric Services. 1998;49:86-90.

8. McGrath JJ, Hearle J, Jenner L, et al. The fertility and fecundity of patients with psychoses. Acta Psychiatrica Scandinavica. 1999;99:441446.

9. Hutchinson G, Bhugra D, Mallett R, et al. Fertility and marital rates in first-onset schizophrenia. Social Psychiatry and Psychiatric Epidemiology. 1999;34:617-621.

10. Nimgaonkar VL. Reduced fertility in schizophrenia: here to stay? Acta Psychiatrica Scandinavica. 1998;98:348-353.

11. Bassett AS, Bury A, Hodgkinson KA, Honer WG. Reproductive fitness in familial schizophrenia. Schizophrenia Research. 1996;21:151160.

12. Fananas L, Bertranpetit J. Reproductive rates in families of schizophrenic patients in a case-control study. Acta Psychiatrica Scandinavica. 1995;91:202-204.

13. Nanko S, Moridaira J. Reproductive rates in schizophrenic outpatients. Acta Psychiatrica Scandinavica. 1993;87:400-404.

14. Nicholson J, Biebel K, Hinden B, et al. Critical Issues for Parents With Mental lllness and Their Families. Worcester, Mass: University of Massachusetts Medical School, Department of Psychiatry, Center for Mental Health Services Research; 2001.

15. Honey A. Psychiatric vocational rehabilitation: where are the consumers' views? Psychiatric Rehabilitation Journal. 2000;23:270-278.

16. Tsang H, Lam P, Ng B, et al. Predictors of employment outcome for people with psychiatric disabilities: a review of the literature since the mid '80s. Journal of Rehabilitation. 2000;66:19-31.

17. Anthony WA, Rogers ES, Cohen M, Davies RR. Relationships between psychiatric symptomology, work skills, and future vocational performance. Psychiatric Services. 1995;46:353-358.

18. Anthony WA. Characteristics of people with psychiatric disabilities that are predictive of entry into the rehabilitation process and successful employment. Psychosocial Rehabilitation. 1994;17:3-13.

19. Dion GL, Tohen M, Anthony WA, et al. Symptoms and functioning of patients with bipolar disorder six months after hospitalization. Hospital and Community Psychiatry. 1988;39:652-657.

20. Glynn SM. Psychopathology and social functioning in schizophrenia. In: Mueser KT, Tarrier S, eds. Handbook of Social Functioning in Schizophrenia. Boston: Allyn \& Bacon; 1998:66-78.

21. Gotlib IH, Lee CM. The social functioning of depressed patients: a longitudinal assessment. Journal of Social and Clinical Psychology. 1989;8:223-237.

22. Serban G. Mental status, functioning, and stress in chronic schizophrenic patients in community care. American Journal of Psychiatry. 1979;136:948-952.

23. Weissman MM, Paykel ES, Siegel R, et al. The social role performance of depressed women: comparisons with a normal group. American Journal of Orthopsychiatry. 1971;41:390-405.

24. Smith TE, Hull JW, Goodman M, et al. The relative influences of symptoms, insight, and neurocognition on social adjustment in schizophrenia and schizoaffective disorder. The Journal of Nervous and Mental Disease. 1999;187:102-108.

25. Evans S, Cloitre M, Koesis JH, et al. Social-vocational adjustment in unipolar mood disorders: results of the DSM-IV field trial. Journal of Affective Disorders. 1996;38:73-80.

26. Bell MD, Lysaker PH. Psychiatric symptoms and work performance among persons with severe mental illness. Psychiatric Services. 1995;46:508-686.

27. Bell MD, Milstein RM, Lysaker PH. Pay as an incentive in work participation by patients with severe mental illness. Hospital and Community Psychiatry. 1993;44:684-686.

28. Harding CM, Hall GM. Long-term outcome studies of schizophrenia: do females continue to display better outcome as expected? International Review of Psychiatry. 1997;9:409-418.

29. Lantz AE, Carlberg CG, Wilson NZ. Mental health treatment outcome by sex, diagnosis, and treatment agency. Professional Psychology: Research and Practice. 1983;14:293-309.

30. McPherson HM. The impact of severe mental illness on a woman. In: Romans SE, ed. Folding Back the Shadows: A Perspective on Women's Mental Health. Dunedin, NZ: University of Otago Press; 1998:251-261. 
31. Andia AM, Zisook S, Heaton RK, et al. Gender differences in schizophrenia. The Joumal of Nervous and Mental Disease. 1995;183:522528.

32. Mowbray CT, Chamberlain P. Sex differences among the long-term mentally disabled. Psychology of Women Quarterly. 1986;10:1-9.

33. Test MA, Burke SS, Wallish LS. Gender differences of young adults with schizophrenic disorders in community care. Schizophrenia Bulletin. 1990;16:331-344.

34. Lehman AF, Rachuba LT, Postrado LT. Demographic influences on quality of life among persons with chronic mental illness. Evaluation and Program Planning. 1995;18:155-164.

35. Haas GL, Garrett LS. Gender differences in social functioning. In: Mueser KT, Tarrier N, eds. Handbook of Social Functioning in Schizophrenia. Boston: Allyn \& Bacon; 1998:149-180.

36. Mowbray CT, Bybee D, Harris SN, McCrohan N. Predictors of work status and future work orientation in people with a psychiatric disability. Psychiatric Rehabilitation Journal. 1995;19:17-28.

37. Gordon RE, Gordon KK. Assessing the elements of biopsychosocial functioning. Hospital and Community Psychiatry. 1991;42:508-512.

38. Brekke JS, Mathiesen SG. Effects of parental involvement on the functioning of noninstitutionalized adults with schizophrenia. Psychiatric Services. 1995;46:1149-1155.

39. Tessler RC, Miller JL, Rossi PH. The chronically mentally ill in the community: what accounts for successful client functioning? Research in Community Mental Health. 1984:4:221-244.

40. Clarkin JF, Hurt SW, Crilly JL. Therapeutic alliance and hospital treatment outcome. Hospital and Community Psychiatry. 1987;38:871875 .

41. Rogler LH. Increasing socioeconomic inequalities and the mental health of the poor. Journal of Nervous and Mental Disease. 1996;184:719722.

42. Bruce ML, Takeuchi DT, Leaf PJ. Poverty and psychiatric status. Archives of General Psychiatry. 1991;48:470-474.

43. Basic Behavioral Science Task force of the NAMHC. Basic behavioral science research for mental health: vulnerability and resilience. American Psychologist. 1996;51:22-28.

44. Robins LN, Helzer JE, Croughan J, et al. National Institute of Mental Health Diagnostic Interview Schedule: its history, characteristics, and validity. Archives of General Psychiatry. 1981;38:381-389.

45. US Bureau of the Census. Poverty Thresholds: 1996 Population Survey. Washington, DC: US Bureau of the Census; 1996.

46. Hollingshead AB. Four Factor Index of Social Status [unpublished manuscript]. New Haven, Conn: Department of Sociology, Yale University; 1975.

47. Skinner HA. The Drug Abuse Screening Test. Addictive Behaviors. 1982;7:363-371.

48. Shern DL, Wilson NZ, Coen AS. Client outcomes, II: longitudinal client data from the Colorado Treatment Outcome Study. Milbank Quarterly. 1994;72:123-148.

49. Calsyn RJ. Prediction perceived service need, service awareness, and service utilization. Journal of Gerontological Social Work. 1993;21:5976.

50. Rosenheck R, Lam J. Client Access Evaluation Form. West Haven, Conn: Northeast Program Evaluation Center; 1994.

51. Barrera M. The Arizona Social Support Inteview Schedule. In: Social Networks and Social Support. Beverly Hills, Calif: Sage Publications; 1988:88-93.

52. Mowbray CT, Jordan LC, Kewalramani A, et al. Analysis of postdischarge change in a dual diagnosis population. Health and Social Work. 1999;24:91-101.

53. Kanner A, Coyne J, Schaefer C, et al. Comparison of two models of stress management: hassles and uplifts versus major life events. Journal of Behavioral Medicine. 1981;4:1-39.

54. Lazarus R, Folkman S. Stress, Appraisal, and Coping. NY: Springer; 1984.

55. Brugha TS, Cragg D. The list of life threatening experiences: the reliability and validity of the Brief Life Events Questionnaire. ACTA Psychiatrica Scandinaica. 1990;82:77-81.

56. Bollen K. Lennox R. Conventional wisdom on measurement: a structural equation perspective. Psychological Bulletin. 1991;110:305-314.

57. Levin SS, Taylor RJ, Chatters LM. A multidimensional measure of religious involvement for African-Americans. Sociological Quarterly. 1995;36:157-173.

58. Wallace CJ. Functional assessment in rehabilitation. Schizophrenia Bulletin. 1986;12:604-624.

59. Weissman MM. The assessment of social adjustment: a review of techniques. Archives of General Psychiatry, 1975;32:357-365.

60. Bybee D, Mowbray CT. Effectiveness of supported education models for people with severe disorders. Poster presented at: The NIMH International Conference on Mental Health Services Research; September 1995; Bethesda, Md.

61. Aiken LS, West SG. Multiple Regression: Testing and Interpreting Interactions. Newbury Park, Calif: Sage; 1991.

62. Mowbray CT, Oyserman D, Bybee D, Callahan J, Maclarlane P. Diagnostic differences among women with long-term, serious mental illness. Psychological Services. In press.

63. Baron RM, Kenny DA. The moderator-mediator variable distinction in social psychological research: conceptual, strategic, and statistical considerations. Journal of Personality and Social Psychology. 1986;51:1173-1182.

64. Jackson AP. Black, single, working mothers in poverty: preferences for employment, well-being, and perceptions of preschool-age children. Social Work. 1993;38:26-34.

65. Anderson NB, Armstead CA. Toward understanding the association of socioeconomic status and health: a new challenge for the biopsychosocial approach. Psychosomatic Medicine. 1995;57:213-225.

66. Mondanaro J. Chemically Dependent Women: Assessment and Treatment. Lexington, Mass: Lexington Books; 1989.

67. Seeman MV. Narratives of twenty to thirty year outcomes in schizophrenia. Psychiatry: Interpersonal and Biological Processes. 1998;61:249-261.

68. Williams CC, Collins AA. Defining new frameworks for psychosocial intervention. Psychiatry. 1999;62:61-78.

69. Lehman AF. Quality of care in mental health: the case of schizophrenia. Health Affairs. 1999;18:52-65.

70. Benn R. A Statewide Definition of Eligibility Under P.L. 99-457, Part H: A Final Research Report. Detroit, Mich: Merrill-Palmer Institute, Wayne State University; 1991. 
71. D'Ercole A. Single mothers: stress, coping, and social support. Journal of Community Psychology. 1988;16(special issue):41-54.

72. Hendryx MS, Ahern MM. Mental health functioning and community problems. Joumal of Community Psychology. 1997;25:147-157.

73. Wijnberg MH, Reding KM. Reclaiming a stress focus: the hassles of rural, poor single mothers. Families in Society. 1999;80:506-515.

74. Weissman MM, Leaf PJ, Bruce ML. Single parent women: a community study. Social Psychiatry. 1987;22:29-36.

75. Steffens PD, Schumm WR. Economic and social-psychological factors as a function of social functioning status among low-income women in Kansas. Psychological Reports. 1999;84:657-661.

76. Sullivan WP. Recoiling, regrouping, and recovering: first-person accounts of the role of spirituality in the course of serious mental illness. New Directions for Mental Health Services. 1998;80:25-33.

77. Walters J, Neugeboren B. Collaboration between mental health organizations and religious institutions. Psychiatric Rehabilitation Journal. 1995;19:51-57.

78. Harding CM, Keller AB. Long-term outcome of social functioning. In: Mueser KT, Tarrier N, eds. Handbook of Social Functioning in Schizophrenia. Boston: Allyn \& Bacon; 1998:134-148.

79. Pancheri P, Romiti R, Marconi PL, et al. Reproductivity in schizophrenia and mood disorders: a retrospective study. New Trends in Experimental and Clinial Psychiatry. 1990;6:29-44.

80. Mowbray CT, Schwartz S, Bybee D, et al. Mothers with mental iliness: stressors and resources for parenting and living. Families \& Society. 2000;81:118-129.

81. Holstein AR, Harding CM. Omissions in assessment of work roles: implications for evaluating social functioning and mental illness. American Journal of Orthopsychiatry. 1992;62:469-474. 


\section{Appendix}

Self-report Community Functioning Scale Items

Mean

SD

1. Thinking about daily chores like cooking, cleaning, laundry, and shopping, which of

3.67

1.19 the following best describes your situation in the past month?

1. Someone else did the chores

2. Someone else did most of the chores, but you helped a little

3. You did some of the chores, but you needed quite a bit of help

4. You did most of the chores, but you needed help with a few things

5. You took care of the chores yourself OR (if living with another adult) you shared the work equally with others living with you

2. Thinking about money and your basic expenses, which of the following best describes your situation in the past month?

1. Someone else managed the money for you

2. You were not able to meet your basic expenses and you had a financial crisis

3. You met your basic expenses, but you needed a lot of help

4. You met your basic expenses, but you needed a little help

5. You met your basic expenses without any help

3. In the past month, did you work, go to school, or do unpaid volunteer work?

(Answer for all activities you did in the past month.)

1. No work, school, or volunteer activity in the past month

3a. Did paid work

2. Work 10 or fewer hours per week

3. Work $11-29 \mathrm{hr}$ per week

4. Work full time ( 30 or more hours per week)

3 b. Went to school

2. Took a single class that was not part of a degree or certification program

3. Part time student in a degree, vocational, or technical program

4. Full-time student in a degree, vocational, or technical program

3c. Did unpaid volunteer work

2. Unpaid volunteer work

(Score for Item 3 is the sum of scores for the three subitems-3a, 3b, and 3c)

4. In the past month, how often have you done something in your free time that was

planned a day or more ahead?

1. Rarely or never

2. Less than once a week

3. Once a week

4. Several times a week (ie, 2-4 times)

5. Nearly every day (ie, 5-7 times)

5. In the past month, which of the following best describes the people you usually talk to?

1. Hardly anyone

2. Your case manager, therapist, or other mental health worker

3. Mostly your case manager or therapist, but occasionally friends or relatives

4. Mostly friends or relatives, but occasionally your case manager or therapist

5. Only friends or relatives 


\begin{tabular}{|c|c|c|}
\hline Self-report Community Functioning Scale Items & Mean & SD \\
\hline $\begin{array}{l}\text { 6. In the past month, how hard has it been for you to join in conversations? } \\
\text { 1. You almost never talked with anyone } \\
\text { 2. You almost never started a conversation, and you had trouble } \\
\text { responding } \\
\text { 3. You almost never started a conversation, but could respond if } \\
\text { someone talked to you } \\
\text { 4. You had some trouble starting up a conversation, but you did it } \\
\text { sometimes } \\
\text { 5. You had no trouble starting up a conversation, and you did it } \\
\text { frequently }\end{array}$ & 3.87 & 1.26 \\
\hline $\begin{array}{l}\text { 7. In the past month, how much conflict have you had with people in your life? } \\
\text { 1. Major conflicts that disrupted a number of relationships } \\
\text { 2. Conflicts that disrupted } 1 \text { or } 2 \text { relationships } \\
\text { 3. Conflicts that strained some relationships but did not disrupt any } \\
\text { 4. Minor conflicts that caused a little strain on } 1 \text { or } 2 \text { relationships } \\
\text { 5. No conflicts that strained any relationships }\end{array}$ & 3.58 & 1.34 \\
\hline $\begin{array}{l}\text { 8. In the past month, how hard has it been to make others understand what you } \\
\text { wanted to say? } \\
\text { 1. Nearly always hard } \\
\text { 2. Often hard } \\
\text { 3. Sometimes hard } \\
\text { 4. Hard a couple of times } \\
\text { 5. Not hard at all }\end{array}$ & 3.12 & 1.28 \\
\hline $\begin{array}{l}\text { 9. In the past month, how often have you felt in control of your feelings and actions? } \\
\text { 1. Hardly ever } \\
\text { 2. Rarely } \\
\text { 3. Sometimes } \\
\text { 4. Most of the time } \\
\text { 5. Nearly all the time }\end{array}$ & 3.39 & 1.08 \\
\hline $\begin{array}{l}\text { 10. In the past month, how often have you felt good about yourself? } \\
\text { 1. Hardly ever } \\
\text { 2. Rarely } \\
\text { 3. Sometimes } \\
\text { 4. Most of the time } \\
\text { 5. Nearly all the time }\end{array}$ & 3.06 & 1.17 \\
\hline $\begin{array}{l}\text { 11. In the past month, how often were you able to keep appointments you had? } \\
\text { 1. Hardly ever } \\
\text { 2. Rarely } \\
\text { 3. Sometimes } \\
\text { 4. Most of the time } \\
\text { 5. Nearly all the time }\end{array}$ & 3.82 & 1.11 \\
\hline $\begin{array}{l}\text { 12. In the past month, how have you handled everyday crises and hassles? } \\
\text { 1. Frequently someone else had to take over and deal with things for you } \\
\text { 2. Occasionally someone else had to take over and deal with things } \\
\text { for you } \\
\text { 3. You needed quite a bit of support and advice from others } \\
\text { 4. You needed a little support and advice from others } \\
\text { 5. You needed no help from others }\end{array}$ & 3.58 & 1.01 \\
\hline
\end{tabular}

(continues) 


\begin{tabular}{|c|c|c|}
\hline Self-report Community Functioning Scale Items (continued) & Mean & SD \\
\hline $\begin{array}{l}\text { 13. In the past month, would you say you have taken your psychiatric medication } \\
\text { exactly as prescribed: } \\
\text { 1. Never } \\
\text { 2. Rarely } \\
\text { 3. Sometimes } \\
\text { 4. Most of the time } \\
\text { 5. All the time OR not prescribed psychiatric medication in the } \\
\text { past month }\end{array}$ & 4.21 & 1.20 \\
\hline $\begin{array}{l}\text { 14. How would you describe your physical health overall during the past month? } \\
\text { 1. Poor } \\
\text { 2. Fair } \\
\text { 3. Good } \\
\text { 4. Very good } \\
\text { 5. Excellent }\end{array}$ & 2.70 & 1.15 \\
\hline $\begin{array}{l}\text { 15. In the past month, have you been limited in any way because of a physical } \\
\text { impairment or health problem? } \\
\text { 1. Frequent serious limitations } \\
\text { 2. Occasional serious limitations } \\
\text { 3. Moderate limitations } \\
\text { 4. Minor limitations } \\
\text { 5. No limitations }\end{array}$ & 3.64 & 1.37 \\
\hline $\begin{array}{l}\text { 16. How troubled or bothered have you been in the past month by alcohol or drug } \\
\text { problems? } \\
\text { 1. Extremely } \\
\text { 2. Considerably } \\
\text { 3. Moderately } \\
\text { 4. Slightly } \\
\text { 5. Not at all }\end{array}$ & 4.71 & 0.86 \\
\hline $\begin{array}{l}\text { 17. In the past month, to what extent have you felt that you needed mental health } \\
\text { services? (INT: any mental health services] } \\
\text { 1. A lot } \\
\text { 2. Quite a bit } \\
\text { 3. Some } \\
\text { 4. A little } \\
\text { 5. Not at all }\end{array}$ & 3.52 & 1.22 \\
\hline $\begin{array}{l}\text { 18. Which of the following best describes how you feel about your relationship with } \\
\text { your therapist or case manager? } \\
\text { 1. You have not paid attention to what your therapist recommends } \\
\text { 2. You followed a little of your therapist's advice } \\
\text { 3. You followed your therapist's recommendations some of the time } \\
\text { 4. You followed your therapist's recommendations most of the time } \\
\text { 5. Your therapist and you worked together on issues that are important } \\
\text { to you }\end{array}$ & 4.05 & 1.42 \\
\hline
\end{tabular}

